\title{
Influence of the Double Cone Drill Geometry on the Holes Quality during Drilling Multi-Stack Made of CFRP/Al
}

\author{
R. Zitoune, N. Cadorin, B. S. Elambouacif, F. Collombet, V. Krishnaraj, and H. Bougherara
}

\begin{abstract}
In this paper, experimental study on drilling of multi-material made of CFRP laminate sandwiched with aluminum part has been carried out. These tests have been conducted using carbide drills (K20) to study the influence of spindle speed, feed rate and lip length of the double cone drill on cutting forces and holes quality. From the experimental study it was found that the double cone drills used for the experimental analysis encountered less thrust force compared to the standard twist drill. In addition the quality of the holes after drilling were evaluated, and found that no delamination (entry and exit of the hole of the composite part) even at higher feed rate ( $>$ to 0.1 $\mathrm{mm} / \mathrm{rev}$ ). From the SEM observation it was noticed that, after machining with standard twist drill, several damaged areas were observed on the wall of the holes.
\end{abstract}

Index Terms-Drilling, multi-stack, Damages, tool design, aluminium chips.

\section{INTRODUCTION}

Drilling and fastening of the hybrid materials in one-shot operation reduces manufacturing time. One of the most common problems encountered during automatic drilling of sandwich structures are that the continuous chips and high temperature generated during drilling of $\mathrm{Ti}$, and damage in composites. LATECIS a French company in Toulouse, developed a system called OPERA, dedicated for one shot drilling. Ideally the OPERA system is expected to handle high production rates (1 attachment mounted approximately at every 12 seconds) [1], [2]. The automation of these tasks must also enable greater mounting precision, improved ergonomics, health and safety of the operators, particularly for the new hybrid materials like composite/titanium or composite/aluminum assemblies. Due to the different mechanical properties of materials constituting the hybrid panels, their machinability remains an open problem and can prevent the automation of these tasks. From the literature review, it is found that composite materials especially Carbon Fibre Reinforced Plastics (CFRP) are often used to a larger extent due to their downsizing and rightsizing impacts. However, due to their laminated structure and the anisotropy of the carbon fiber reinforce plastics several damages are seen during drilling. The damages are peel up delamination at the hole entry, thermal alteration, fibre pull-out and fuzzing on the wall of the hole, and exit delamination and uncut fibre at the hole exit [3]-[5]. Moreover, the mechanism of material removal in composite materials is strongly influenced by the relative angle between the direction of the cutting speed and

Manuscript received January 10, 2014; revised March 26, 2014.

The authors are with the Mechanical Engineering Department, Pau Sabatier University (University of Toulouse, France), France (e-mail Redouane.zitoune@iut-tlse3.fr). the direction of fiber [6]. Sakuma et al. [4] drilled holes using four drill materials and investigated drill wear pattern, flank wear width and cutting forces. Many researchers investigated the effect of tool geometry on drilling of polymer composite materials. Many of the modified geometries (Zhirov point, Brad and Spur, step drill, candle stick, saw drill, etc) are difficult to regrind [5]. Krishnaraj et al. [7] drilled composites at high spindle speed and studied the influence of tool geometry. They reported that double cone drill offers better surface finish when compared to standard twist drill and Brad \& Spur drill. In particular double cone drills which the length of the principal cutting edge is equal to the length of the secondary cutting edge offer better finish [7], [8].

Unlike composites, the material removal during machining of aluminium is mainly done by shearing the material. In the case of drilling of aluminium and its alloys, the main problem is the adhesion of aluminium on the main cutting edges (BUE), on the rake face and on the flutes of the drill (BUL). This bonding is responsible for premature wear of the cutting tool, for the poor surface finish of the hole and the variations in the diameter of the hole. Several authors showed that, with low cutting speeds (up to $25 \mathrm{~m} / \mathrm{min}$ ), bonding of aluminium occurs at the rake face and at the main cutting edges [9]-[11]. One way to overcome problems related to the machining of aluminium and its alloys is to increase cutting speeds. However the machining with very high cutting speeds (Eg. $300 \mathrm{~m} / \mathrm{min}$ ) causes a significant increase in the cutting temperature (above $300{ }^{\circ} \mathrm{C}$ ) [11]. At this temperature a chemical reaction between aluminium and cobalt occurs to form micro welding of aluminium on the cutting edges of the tool by diffusion. In the experimental works of [12], [13], the authors during the dry turning of aluminium alloy have shown that, in the first time of machining, BUL is caused by thermo-mechanical mechanisms. Once the BUL is formed, the initial cutting conditions change thus enabling the BUE formation through mechanical adhesion. However, during continuous machining, the BUE continues to grow until a critical thickness is reached, and once it reaches the point, it is plastically extended over the BUL due to the action of the mechanical forces.

Additionally, the chips shape and length of the chip passing through the hole as well as built up edges of aluminium at the primary cutting edges combined with increased tool wear affect the hole quality [1], [2], [14]. For machining multi-material, sharp and high hot hardness tool materials are required. [15], [16] reported that tool wear occur rapidly when drilling $\mathrm{Gr} / \mathrm{Bi}-\mathrm{Ti}$ stacks. Multimaterial theoretically calls for different tools, one that fits the attributes of a composite and a different one that fits the attributes of aluminium, or Titanium. Multilayer materials drilled with adapted step drills improved diameter tolerances, 
surface quality, and reduced tool wear [14].

Ref. [15] and [16] have studied drilling of Gr/Bi-Ti in the context of process conditions and cost optimisation.

Among the various tool geometries investigated, double cone drill was found to offer many advantages when compared to the modified geometries. Only a few investigations on drilling of CFRP laminates using double cone drill have been reported. In literature, the double cone drills are optimized for drilling of metallic materials (steel or aluminum). However, there is little information about the influence of the geometry of the double cone drill on the quality of holes machined. This study attempts to achieve this objective. In this paper, experimental study on drilling a hybrid material made of CFRP laminate aluminum part has been carried out using carbide drills (K20) to study the influence of spindle speed, feed rate and lip length of the double cone drill on thrust force and hole quality.

\section{EXPERIMENTATION PROCEDURE}

\section{A. Workpiece Details}

The sandwich plates studied are composed of a carbon/epoxy and aluminium. The CFRP composite specimen used in the investigation was $4.2 \mathrm{~mm}$ thick. The laminate was made out of 16 unidirectional plies of $0.26 \mathrm{~mm}$ thickness each. The 16 unidirectional plies are made of carbon/epoxy prepreg and manufactured by Hexcel Composite Company with the reference T700-M21. The following was the staking sequence $[90 / 45 / 0 /-45]_{2 s}$. These materials were compacted using a vacuum pump in a controlled atmosphere. A mould for the laminate was prepared and placed in a vacuum bagging and evacuated to 0.7 bar (see. Fig. 1a). Curing was then carried out at $180{ }^{\circ} \mathrm{C}$ for 120 min during which the pressure was maintained at 7 bar in an autoclave. Fig. 1b shows the laminate used for conducting the experiments. The aluminum alloy used in this study is extensively used in aviation industry have referenced as $\mathrm{Al}$ 2024. The percentage of alloying elements is as follows: $\mathrm{Al} 93.5 \% \mathrm{Si} 0.5 \%, \mathrm{Cu} 3.8-4.9 \%, \mathrm{Mg} 1.2-1.8 \%, 0.1 \% \mathrm{Cr}$.

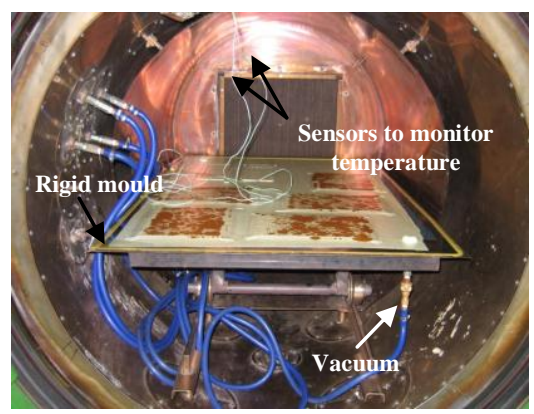

Fig. 1. Manufacturing of the composite part by the autoclave process.

\section{B. Drilling Details}

Drilling is done on a CNC machine developed by LATECIS Company (Toulouse, France) under the research project OPERA (Automated drilling and riveting of aircraft structures) is shown in Fig. 1a. The acquisition of cutting forces is carried out using a four-component Kistler dynamometer as shown in Fig. 2a. The dynamometer is connected to a Kistler charge amplifier type 5019. The output of the amplifier is transformed into a cutting force through a computer that stores the force signals versus cutting time. The sandwich panel to be drilled is clamped on a dedicated support (see Fig. 2b). On the latter, a hole of $18 \mathrm{~mm}$ is machined to allow the drill bit and to prevent the bending of the sandwich plate. The drilling tests performed are based on full factorial experimental design using three feed rates $(0.05$ $\mathrm{mm} / \mathrm{rev}, 0.1 \mathrm{~mm} / \mathrm{rev}$ and $0.15 \mathrm{~mm} / \mathrm{rev}$ ) and two spindle speeds (2020 rpm and $2750 \mathrm{rpm}$ ). Characteristics geometric of the reference tool (ref-tool) marketed by French industry for drilling of composite materials for Air-Bus industries is presented in Fig. 3a, and the same has been modified to double cone geometry. The modification of the tool geometry is achieved using a 5-axis grinding machine.

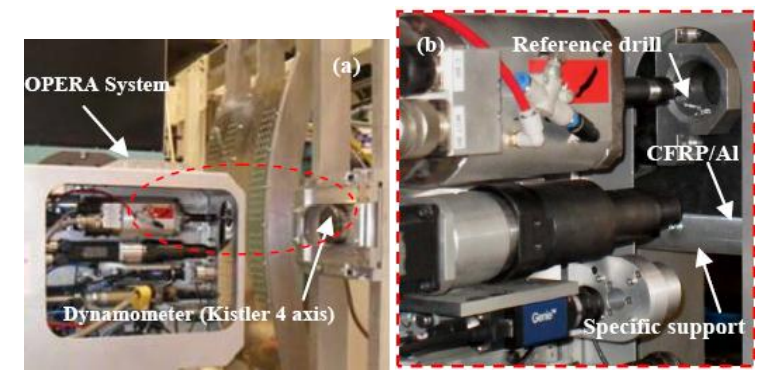

Fig. 2. Experimental device for drilling tests. With: (a) Front view of OPERA system, (b) Zoom of the area surrounded area of (a).
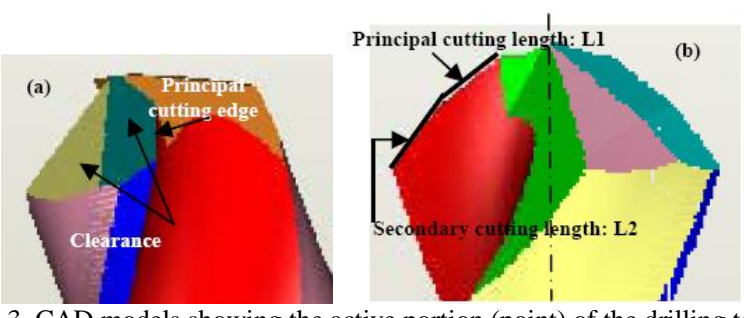

Fig. 3. CAD models showing the active portion (point) of the drilling tools with (a) reference tool (b) double cone tool.

The double cone tools measure $90^{\circ}$ and $132^{\circ}$ point angles with cutting edge lengths, namely L1 and L2 (see Fig. 3) while L1 represents the size of the principal cutting edge number 1 which is characterized by a point angle of $132^{\circ}, \mathrm{L} 2$ represents the size of principal cutting edge number 2 which is characterized by a point angle of $90^{\circ}$. The double cone drills tested are ground with different L1/L2 ratios, in which M1, M2 and M3 represent L1/L2 ratios of 0.33, 1 and 3.1 respectively. Drilling trials were carried out using a $6.35 \mathrm{~mm}$ of diameter made of tungsten carbide (K20). For the confidentiality reasons is not possible to give more details about the geometry of the tools. Each experimental condition was repeated 5 times in order to get consistent values. To remove the influence of tool wear, each experiment was performed with a new drill.

The quality of the machined surface (wall of the hole) is quantified using the SEM observation and the surface roughness. The surface roughness (Ra) of the hole was measured by surface roughness tester (Mitutoya SJ 500) with a sampling length (cut-off) of $0.8 \mathrm{~mm}$. In case of CFRP the length of measurement through the hole was $4 \mathrm{~mm}(0.8 \times 5=$ $4 \mathrm{~mm})$.

\section{RESULTS AND DISCUSSION}

\section{A. Cutting Force Analysis}

Fig. 4 represents the evolution of the thrust forces during 
drilling with reference drill, double cone drill M2 and for machining parameters of $0.05 \mathrm{~mm} / \mathrm{rev}$ of feed rate at a spindle speed of $2020 \mathrm{rpm}$. From this figure it is noticed that, the increasing of the second cutting length leads to reduce the thrust forces. If we plot the average value of the cutting forces for all tested tools and for various feed speed, it is observed that, drilling with the reference tool experiences higher thrust force compared to the double cone tools (see Fig. 5).

When the feed rate has been increased from $0.05 \mathrm{~mm} / \mathrm{rev}$ to $0.15 \mathrm{~mm} / \mathrm{rev}$, the drilling with the reference tool is subjected to an increase of $60 \%$ of the total thrust force in the composite (with the maximum value of $126 \mathrm{~N}$ ) and $158 \%$ in the aluminum (with the maximum value of $481 \mathrm{~N}$ ). This result observed while drilling at a spindle speed of $2020 \mathrm{rpm}$. Similar increase of thrust forces are observed when drilling with double cone tools as well. However, for the same machining parameters, drilling with double cone tools produce $15 \%$ to $30 \%$ lesser thrust force in the composite when compared to the thrust produced when machining with a reference tool. This can be explained by the fact that adding a secondary point angle $\left(90^{\circ}\right)$ reduces the theoretical average chip thickness by $15 \%$. From the literature works focused the orthogonal cutting on unidirectional composite material; various authors have shown that, the increasing of the depth of cut (chip thickness) lead to increase of the cutting forces. During drilling at a spindle speed of $2750 \mathrm{rpm}$, similar results are obtained compared a spindle speed of $2020 \mathrm{rpm}$.

The evolution of the thrust force generated during drilling of aluminum vs. the feed rate show that, the level of the recorded forces induced by the reference drill and the double cone drill M2 and M3 are similar. However, the double cone drill M1 induces a less thrust force. This difference can be attributed to the fact that, adding a secondary point angle $\left(90^{\circ}\right)$ on the one hand reduces the theoretical average chip thickness and on the other hand increase the surface contact between the drill bit and the aluminum part. This increasing of the surface contact leads to increase the friction. This can be confirmed thanks to torque level recorded vs. the feed rates and tool geometries (see Fig. 6).

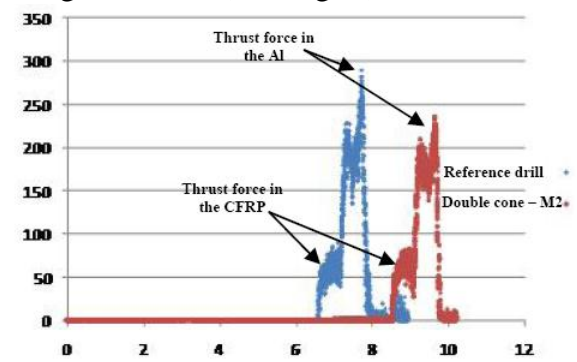

Fig. 4. Thrust force evolution during time of drilling for different tool geometries.

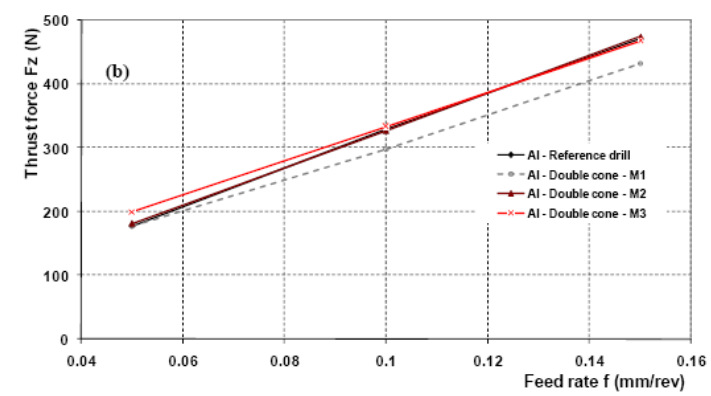

Fig. 5. Influence of the tool geometry and feed rate on the thrust force during drilling at a spindle speed of $2020 \mathrm{rpm}$. (a): thrust force in the composite, (b): thrust force in the aluminum.

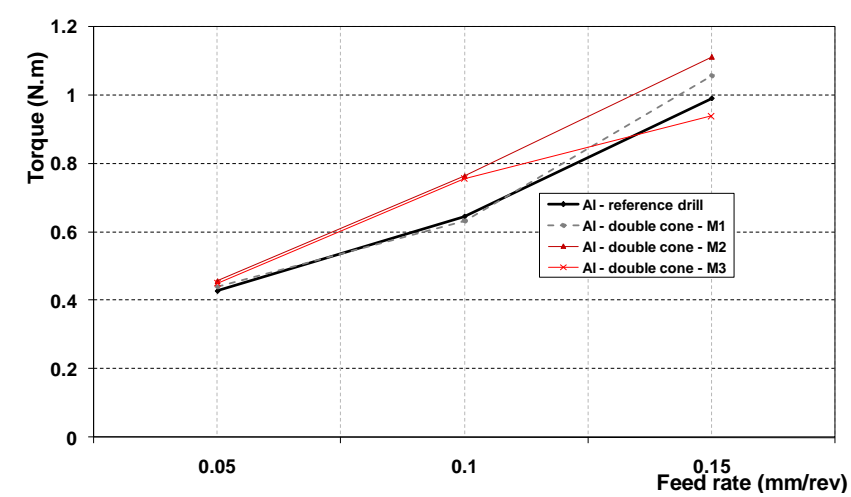

Fig. 6. Influence of the machining parameters and the tool geometry on the torque during drilling aluminum.

\section{B. Quality of the Machined Holes}

Fig. 7 and 8 show the effect of drill geometry on surface finish at various feed rates, for a spindle speed of $2020 \mathrm{rpm}$ in the CFRP and aluminium respectively. Experimental results can reveal that at a low feed rate $(<0.1 \mathrm{~mm} / \mathrm{rev})$, the quality of the machined surface is better for any drill used. In this case, values of the measured roughness are smaller $(<3 \mu \mathrm{m})$. Further it can also be observed that, for all machining parameters used, values of the surface roughness obtained with the reference tool are inferior when compared to those obtained with double cone tools. This difference can be linked to the interaction between the size of chip thickness and the drill point angle. In addition, double cone drills favour the apparition of continues chips during drilling of aluminium. For this small roughness are obtained on the wall of aluminium holes when drilling is conducted with double cone drills compared to the reference drill.

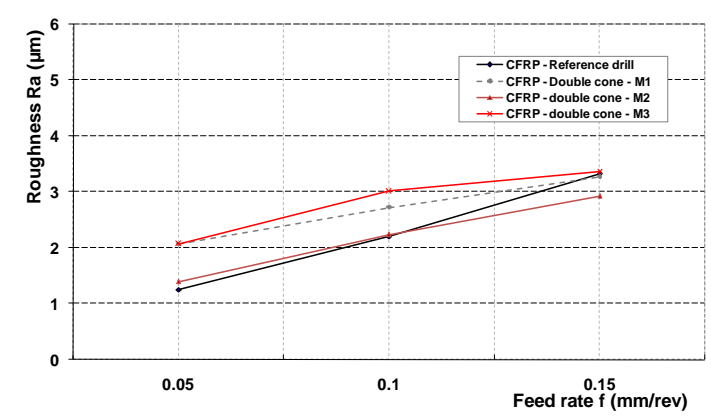

Fig. 7. Evolution of the roughness in the CFRP vs. feed rate for reference drill and double cone drills at a spindle speed of $2020 \mathrm{rpm}$.

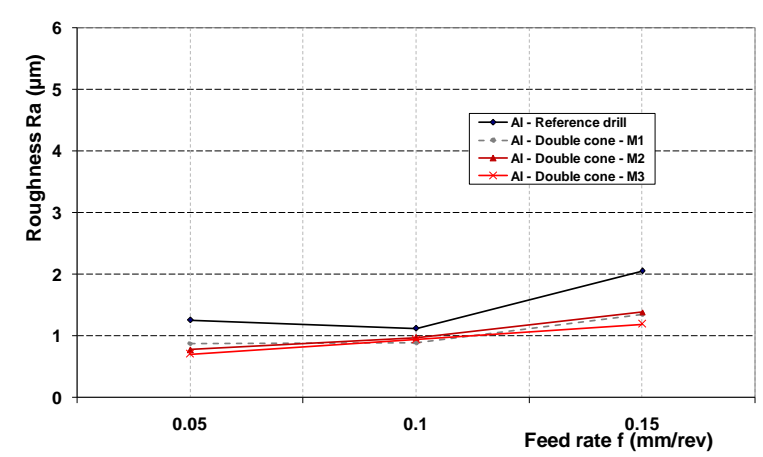

Fig. 8. Evolution of the roughness in the aluminum vs. feed rate for reference drill and double cone drills at a spindle speed of $2020 \mathrm{rpm}$.

With the increasing if the length of second edge of the double cone drills we reduce the chip thickness and we improve the machining quality (see Fig. 8). Drilling with double cone drills offer stable surface roughness (inferior to 
$1 \mu \mathrm{m})$ in the aluminium when machining is conducted with feed rates between 0.05 and $0.1 \mathrm{~mm} / \mathrm{rev}$ and for any spindle speed (2020 rpm or $2750 \mathrm{rpm})$. However in the same machining parameters machining with reference drill gives a roughness values superior to $1 \mu \mathrm{m}$. In addition, for all tools used, drilling with $0.15 \mu \mathrm{m}$, the roughness measured in the aluminium is superior to $1 \mu \mathrm{m}$.

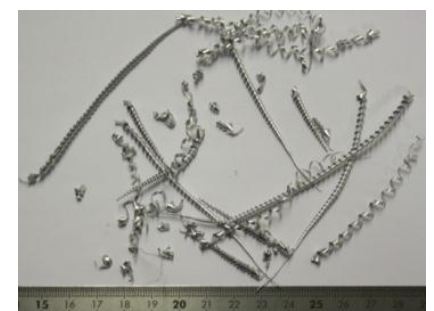

(a)

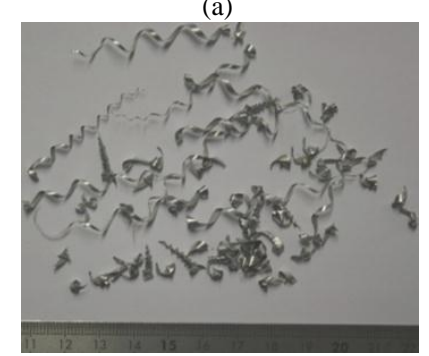

(b)

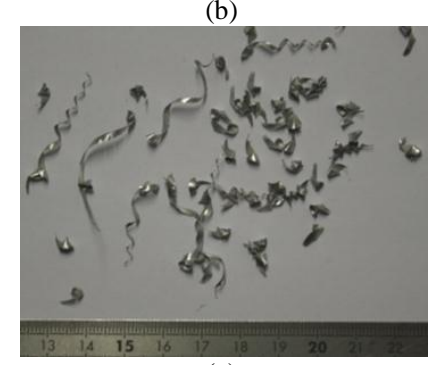

(c)

Fig. 9. Influence of the feed rate on the aluminum chips after drilling with double cone drill M2. With: (a) $N=2020 \mathrm{rpm}, f=0.05 \mathrm{~mm} / \mathrm{rev}$, (b) $N=2020$ $\mathrm{rpm}, f=0.1 \mathrm{~mm} / \mathrm{rev}$, (c) $N=2020 \mathrm{rpm}, f=0.15 \mathrm{~mm} / \mathrm{rev}$.
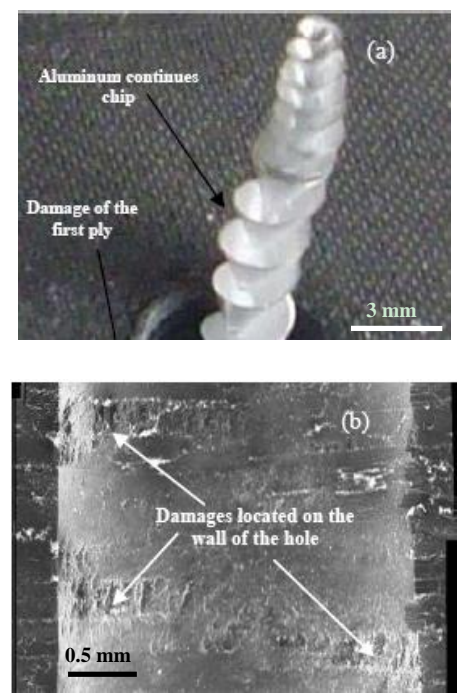

Fig. 10. Different nature of damage observed when drilling is conducted with small feed rate $(0.05 \mathrm{~mm} / \mathrm{rev}$, spindle speed of $2020 \mathrm{rpm})$ and for all the tested drills. (a): Chips flow, (b): damages on the wall of the CFRP hole.

Generally, drilling with double cone drill M2 give better machining quality. Specially, drilling with a feed rate of 0.1 $\mathrm{mm} / \mathrm{rev}$ and using the double cone tool (M2) offers a small roughness at both the spindle speeds in the composite and aluminium holes (roughness in the CFRP inferior to $3 \mu \mathrm{m}$ and in the aluminum inferior to $1 \mu \mathrm{m})$. In addition drilling with a feed rate of $0.1 \mathrm{~mm} / \mathrm{rev}$ favors the apparition of broken aluminum chips. The stable surface roughness value beyond $0.1 \mathrm{~mm} / \mathrm{rev}$ could be due to the wiping effect of the primary cutting edge 2 .

It is important to mentioned that, the drilling with a small feed rate $(0.05 \mathrm{~mm} / \mathrm{rev})$ favors the apparition of continues chips for all used tools (see Fig. 9). With these continues chips two problems have been observed when the OPERA system is used. The first problem is the interaction of these chips with the composite, leads to the degradation of the first ply of the CFRP part located at the hole entry as well as the damages apparition on the wall of the hole (see Fig. 10). The second problem is the aspiration system malfunction of carbon dust.

\section{CONCLUSION}

From the experimental study carried out during drilling of multi-material made of CFRP/Aluminium, using different double cone drills, the following conclusions can be drawn:

- Drilling using double cone drill presents, lesser thrust force when compared to drilling using the reference drill. Especially the drilling using double cone drill (Type M2) resulted in reduced average roughness values when compared to other double cone drills and reference drill at $0.1 \mathrm{~mm} / \mathrm{rev}$ feed rate. Also when drilling an isotropic material such as steel or titanium with double point angle, it has been recommended [34] that the ratio of the second cutting edge to the principal cutting edge (L2/L1) is to be equal to 0.15 . One can conclude that it is suggested to use double cone drills with $\mathrm{L} 2 / \mathrm{L} 1$ equal to 1 when drilling CFRP materials.

- No push-out delamination was observed even at higher feed rate above $0.1 \mathrm{~mm} / \mathrm{rev}$. This can be attributed to the aluminium plate at the bottom of the laminate and also to the presence the small thrust forces.

- $\quad$ The presence of continues chips (aluminium) at low feed rate impact the hole quality of the composite by the presence of the peel up delamination at the top of the hole.

\section{ACKNOWLEDGMENT}

The author's sincerely thank Midi-Pyrénées Region (French) for their financial support.

\section{REFERENCES}

[1] R. Zitoune et al. "Influence of machining parameters and new nano-coated tool on drilling performance of CFRP/Aluminium sandwich," Composites Part B: Engineering, vol. 43, no. 3, pp. 1480-1488, 2012.

[2] R. Zitoune, V. Krishnaraj, and F. Collombet, "Study of drilling of composite material and aluminum stack," Composite Structures, vol. 92, pp. 1246-1255, 2010.

[3] S. Abrate, "Machining of composites," in Composites Engineering Hand Book, P. K. Mallick, Ed. Marcel Deckker Inc., New York, pp. 777-807, 1997.

[4] Y. S. Sakuma, "Study on drilling of reinforced plastics (GFRP \& CFRP)-Relation between tool material and wear behavior," Bulletin of $J S M E$, vol. 27, no. 228, pp. 1237-1244, 1984.

[5] C. C. Tsao and H. Hocheng, "Taguchi analysis of delamination associated with various drill bits in drilling of composite material," Int. J. Machine tools \& Mfr., vol. 44, pp. 1085-1090, 2004.

[6] R. Zitoune, Collombet et al., "Experiment-calculation comparison of the cutting conditions representative of the long fibre composite 
drilling phase," Comp. Sc. and Tech., vol. 65, no. 3-4, pp. 455-466, 2005.

[7] V. Krishnaraj and S.Vijayarangan et al., "An investigation on high speed drilling of GFRP," Indian journal of Engineering and Materials Sciences, vol. 12, pp. 189-196, 2005.

[8] R. Zitoune, M. E. Mansori, and V. Krishnaraj, "Tribo-Functional design of double cone drill implications in tool wear during drilling of copper mesh/cfrp/Woven ply," Wear, vol. 302, no. 1-2, pp. 1560-1567, 2013.

[9] B. Chamberlain, Metals Handbook, ASM, 1998.

[10] G. List, M. Nouari, D. Géhin, S. Gomez, P. Manaud, and Y. L. Petitcorps et al., "Wear behaviour of cemented carbide tools in dry machining of aluminium alloy," Wear, vol. 259, pp. 1177-1189, 2005.

[11] M. Nouari, G. List, F. Girot, and G. Géhin, "Effect of machining parameters and coating on wear mechanisms in dry drilling of aluminium alloys," Int J Mach Tools Manuf, vol. 45, pp. 1436-1442, 2005.

[12] M. S. Carrilero, R. Bienvenido, J. M. Sanchez, M. Alvarez, A. Gonzalez, and M. Marcos, "A SEM and EDS insight into the BUL and BUE differences in the turning processes of AA2024 Al-Cu alloy," Int J Mach Tools Manuf, vol. 42, pp. 215-220, 2002.

[13] J. M. Sanchez, E. Rubio, M. Alvarez, M. A. Sebastien, and M. Marcos, "Microstructural characterisation of material adhered over cutting tool in the dry machining of aerospace aluminium alloys," J. Mater Process Technol, pp. 164-665, 911-918, 2005.
[14] E. Brinksmeier et al., "Drilling of multi-layer composite materials consisting of carbon fibre reinforced plastics (CFRP)," Titanium and aluminum alloys, Annals of the CIRP, vol. 51, pp. 87-90, 2002.

[15] D. Kim et al., "Drilling process optimization for graphite/bismaleimide-titanium alloy stacks," Composite Structures, pp. 101- 114, 2004.

[16] M. Ramulu et al., "A study on the drilling of composite and titanium stacks," Composite Structures, vol. 54, pp. 67-77, 2001.

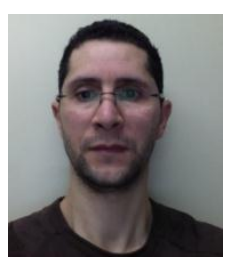

Redouane Zitoune was born in 1976. He is an associate professor in mechanical engineering at Paul Sabatier University (University of Toulouse, France), since 2005. The PhD work of Redouane Zitoune is focused on machining (drilling and milling) of composites materials. His current research interests include damage analysis during drilling and milling of composites materials (with conventional machining and abrasive water jet machining) and finites elements simulation of machining. He is also interested in the thermal analysis of composites structures by using an optical fibres and finite element analysis. He has published more than 60 technical papers in National and International Journals/conferences. In the area of machining of composites materials he has organized the first national meeting in May 2012. This scientific event has been organized with the collaboration of the French Aerospace Lab (ONERA) and with the consent of the national Association for Composites MAterials (AMAC). 